J. Clin. Chem. Clin. Biochem.

Vol. 19, 1981, pp. 1027-1031

\title{
An Evaluation of the Automated OLLI CD Discrete Analyser
}

\author{
By G. A. Harff and C. van Leeuwen \\ Academical Hospital, Free University, Department of Clinical Chemistry, Amsterdam, The Netherlands
}

(Received December 10, 1980/March 2, 1981)

Summary: We report the evaluation of a novel clinical chemical analyser, the OLLI CD, which is highly automated compared to its predecessor, the OLLI 3000 analyser.

The precision of the dispensing unit, the OLLI D, was assessed with the aid of aqueous solutions of ${ }^{131}$ I. Sample pipetting of $10 \mu \mathrm{l}$ resulted in a coefficient of variation of $0.81 \%$. Lower volumes were unreliable. However, precision of the addition of start reagent for kinetic methods appeared to be only $2.7 \%$ for $20 \mu 1,1.7 \%$ for $50 \mu 1$ and $2.1 \%$ for $250 \mu \mathrm{l}$.

The linearity of response and the precision of the photometer unit, the OLLI C, was assessed with cobalt(II)sulfate solutions. The linearity ranged up to an absorbance of 2.5 . The reproducibility of the colorimeter ranged from As10nm 0.0011 to 0.0047 .

With this analyser good correlations were obtained for alanine aminotransferase (EC 2.6.1.2) vs LKB 8600 reaction rate analyser; for creatinine vs Mark II Autoanalyzer; and for total protein vs SMA 6/60 Autoanalyzer. These three determinations showed acceptable between-day variations.

General instrument performance was acceptable.

\section{Evaluation des automatischen OLLI CD diskreten Analysensystems}

Zusammenfassung: Wir evaluierten ein neues klinisch-chemisches Analysensystem, OLLI CD, das hoch automatisiert ist im Vergleich mit dem älteren OLLI 3000 System.

Die Präzision der Pipettieranlage, OLLI D, wurde gemessen mit Hilfe von wäßrigen Lösungen von ${ }^{131}$ I. Pipettierung von $10 \mu 1$ Probe ergab einen Variationskoeffizienten von $0.81 \%$. Niedrigere Volumina sind unsicher. Die Präzision der Zugabe von Startreagenz für kinetische Verfahren betrug nur $2.7 \%$ für $20 \mu \mathrm{l} ; 1.7 \%$ für $50 \mu \mathrm{l}$ und $2.1 \%$ für $250 \mu \mathrm{l}$.

Die Linearität der Absorption und die Präzision des Photometers, OLLI C, wurden mit Hilfe von Kobalt(II)sulfatlösungen geprüft. Die Absorptionsmessung ist bis $A_{510 \text { nm }}=2,5$ linear. Die Reproduzierbarkeit des Kolorimeters war $A_{510 \mathrm{~nm}}=0,0011$ bis 0,0047.

Dieses OLLI CD System ergab gute Korrelationen für Alaninaminotransferase (EC 2.6.1.2) vs LKB 8600 Reaction Rate Analyser; für Kreatinin vs Mark II Autoanalyzer und für Gesamteiweiß vs SMA 6/60 Autoanalyzer. Diese drei Methọen zeigten akzeptierbare Tag zu Tag-Variationen.

Die generelle Handhabung des Geräts kann als annehmbar bezeichnet werden.

\section{Introduction}

The lateșt development in automatic clinical analysers by the KONE OY company is the OLLI CD. This instrument is an innovation of the OLLI 3000 , which was introduced in the early seventies and evaluated by Fröhlich et al. (1). The OLLI CD consists of two modules; the $C$ is the colorimeter unit and the $D$ is the sample dispenser.

The OLLI D sample dispenser is a PROM processed pipettor system with 8 syringes. The syringes are con- nected to the dispensing needles by polyethylene tubing. All 8 syringes are simultaneously moved by one stepper motor. Dispensing is performed into a block containing 24 cuvettes, arranged in 3 rows of 8 cuvettes. It is appropriate to describe the events in the needle-tubing-syringe system during functioning of the dispenser. After activation of the dispenser head a washing cycle is performed. Then a $30 \mu \mathrm{l}$ air segment is introduced into the needle before sucking up $10 \mu \mathrm{l}$ of reagent; again $30 \mu \mathrm{l}$ air is sucked up, followed by the programmed volume of reagent. Before taking in the serum sample, another air 
segment of $30 \mu \mathrm{l}$ is introduced. Thus separation of washing liquid (demineralized water), reagent and serum sample is maintained by $30 \mu \mathrm{l}$ air segments in each needle-tubing-syringe system, preventing mixing of washing liquid with the reagent. The blocks can be thermostated at 25,30 or $37^{\circ} \mathrm{C}$. The sample and reagent volumes are selectable from 5 to $1000 \mu \mathrm{l}$ in $1 \mu \mathrm{l}$ increments. Operational changes can be easily programmed on a keyboard. Recently (March 1980), the washing procedure was basically changed by introducing a waterflow-through accessory attached to the syringes. This technical adaption ensures a better cleaning of the needle-tubing-syringe configuration and consequently improves its precision. All experiments described here were performed after this alteration.

The OLLI C is an Intel 8080 microcomputer-processed colorimeter. The analyses programs are loaded by tape. The latest OLLI program version 4.1 contains 25 methods. The 24 cuvettes in a block each need a minimal volume of $400 \mu$ l for measuring the absorbance in the colorimeter. When a block with properly filled cuvettes is placed into the colorimeter, all 24 cuvettes are illuminated simultaneously by a xenon light source through quartz fibre bundles. Twentyfour photodiodes record the changes in light intensity. Twelve different interference filters can be chosen in the wavelength range $340-800 \mathrm{~nm}$. The analyses can be either kinetic, twopoint kinetic or equilibrium. The OLLI $C$ is electronically coupled to the OLLI D unit, thus allowing for fixed delay time procedures.

We used alanine aminotransferase, creatinine and total protein determinations in order to test the instrument for the three aforementioned test principles.

\section{Materials and Methods}

\section{Apparatus}

OLLI CD (KONE OY, SF-0232 Espoo, Finland). The OLLI C was instructed by tape with OLLI program version 3.2. Mark II Autoanalyzer and SMA 6/60 Autoanalyzer (Technicon Instruments Corporation, Tarrytown, NY 10591, U.S.A.). LKB 8600 reaction rate analyser and LKB 1280 Ultragamma Wallac counter (LKB Clinicon AB, Bromma, Sweden).

\section{Chemicals}

${ }^{131}$ I, $370 \mathrm{GBq} / 1$, Amersham Nederland B. V.; cobalt(II)sulfate, BDH Chemicals Ltd., England; sodium hydroxide and picric acid from E. Merck, F.R.G. (reagent-grade materials).

\section{Reagents and procedures}

Alanine aminotransferase determination: for OLLI CD and LKB 8600, UV-PT working solution No. 3161 and 2-oxoglutaric acid No. 3162 were obtained from J. T. Baker Chemicals B.V., The Netherlands. The assay conditions were according to the recommendations of the Nederlandse Vereniging voor Klinische Chemie (2), with the exception that pyridoxal 5-phosphate was omitted to prevent elevation caused by enhanced apoenzyme in the case of pregnancy (3).

Creatinine determination: for OLLI CD, a final concentration of $105 \mathrm{mmol} / \mathrm{l}$ sodium hydroxide and $7 \mathrm{mmol} / 1$ picric acid was used, according to the semi-kinetic Jaffé method described by Kammeraat (4); for the Mark II Autoanalyzer, Technicon method
AAII-11 with manifold No. 170-A009-01 was adopted. Reagents were obtained from Technicon Instruments. The method is based on the automated Jaffe method as described by Chasson et al. (5).

Total protein determination: for OLLI CD, kit No. 124.281 was purchased from Boehringer Mannheim GmbH, F.R.G., based on the method of Weichselbaum (6); for the SMA 6/60 Autoanalyzer, Technicon method No. SF4-0014FC4 was followed. Reagents were obtained from Technicon Instruments. The Technicon total protein method is based on the work of Skeggs et al. (7), who automated the manual method of Weichselbaum.

\section{Specimens}

Calibration serum for creatinine and total protein was Calibrate Automated Lock-in lot 4G696, lyophilised human serum, from General Diagnostics, U.S.A.

Control sera were Autonorm bovine lot 218 from Nyegaard Co. Norway, bovine serum lot 0864058 from General Diagnostics, U.S.A. and bovine serum lot K 5444-1 from Wellcome Reagents Ltd., England.

Routine patients' sera from our hospital were used in the correlation studies. The specimens were collected in evacuated blood collection tubes, centrifugated within $15 \mathrm{~min}$ of clotting. Serum was assayed on the appropriate reference instruments, the interval of testing between instruments being less than $3 \mathrm{~h}$.

\section{Results and Discussion}

\section{Precision and accuracy of OLLID}

The performance of the dispenser, the $D$ unit, was assessed by a radioactive and a weighing procedure. In order to reduce radioactive contamination of this routine instrument we chose an isotope with short half life,${ }^{131}$ I $\left(\mathrm{T}_{1 / 2}=8.07 \mathrm{~d}\right)$, as the sodium salt in aqueous solution. The precision of sample pipetting was tested in the range of 5-50 $\mu$, the most commonly used sample volumes on the OLLI CD (tab. 1). Good coefficients of variation were obtained down to $10 \mu \mathrm{l}$, but we judged lower volumes to be unreliable.

Tab. 1. Precision of sample dispensing. For all volumes $\mathrm{N}=48$.

\begin{tabular}{cl}
\hline $\begin{array}{l}\text { Volume } \\
(\mu \mathrm{l})\end{array}$ & $\begin{array}{l}\mathrm{CV} \\
(\%)\end{array}$ \\
\hline 5 & 1.21 \\
10 & 0.81 \\
20 & 0.64 \\
50 & 0.49 \\
\hline
\end{tabular}

In kinetic and two-point kinetic measurements a starting reagent is added and the change in light absorbance is measured in the colorimeter after a fixed delay time. In this starting procedure the dispenser takes the reagent for the three rows of eight cuvettes at the same time. This procedure is limited to a maximal volume of $300 \mu \mathrm{l}$ per cuvette.

To test the precision of addition of the starting reagent to the cuvettes, volumes of $20,5.0$ and $250 \mu \mathrm{l}$ of ${ }^{131} \mathrm{I}$ solution were chosen (tab. 2). Coefficients of variations ranged from $1.7 \%$ to $2.7 \%$. The precision of the starting procedure was found to be considerably less than that of 
Tab. 2. Precision of starting reagent dispensing. For all volumes $\mathrm{N}=48$.

\begin{tabular}{cl}
\hline $\begin{array}{l}\text { Volume } \\
(\mu 1)\end{array}$ & $\begin{array}{l}\text { CV } \\
(\%)\end{array}$ \\
\hline 20 & 2.7 \\
50 & 1.7 \\
250 & 2.1 \\
\hline
\end{tabular}

the sample dispensing. The main reason for this observation is a deviation in the dispensing in the third row, as demonstrated by the weighing experiments (see further). The influence of this 'third row' phenomenon on enzyme assays will be almost negligible, because the substrate concentrations usually show a broad optimum. This potential source of error will not be negligible, if colour development in an assay is proportional to the added volume of starting reagent.

To assess the absolute volumes pipetted, the starting procedure was carried out 4 times with $250 \mu \mathrm{l}$ and quantities checked by weighing. The mean values were calculated for the first row dispensed as well as for the second and for the third row. The values obtained were corrected for upward pressure caused by the displaced air during weighing (tab. 3). It appeared that the dispensed volume in the third row of cuvettes was lower than both the first and second row. Utilizing Student's t-test this difference was calculated to be significant. The dispensed volume in the first row and the second row did not differ significantly (first to third, $t=6.69$; second to third, $t=5.86$ and first to second, $t=0.32$ ).

The imprinted keyboard value of $250 \mu$ l was significantly higher than the mean volume dispensed in the first row as well as in the second row $(t=22.5)$. The percent

Tab. 3. Accuracy of starting reagent dispensing. For all volumes $\mathbf{N}=32$.

\begin{tabular}{lll}
\hline Row & $\begin{array}{l}\text { Mean volume } \\
(\mu \mathrm{l})\end{array}$ & $\begin{array}{l}\text { Deviation } \\
(\%)\end{array}$ \\
\hline First & 248.57 & 0.57 \\
Secoñd & 248.60 & 0.56 \\
Third & 247.35 & 1.06 \\
\hline
\end{tabular}

deviation from $250 \mu \mathrm{l}$ for the first, second and third row being $0.57 \%, 0.56 \%$ and $1.06 \%$ respectively. However, these absolute differences in volume added during the starting procedure do not seriously affect clinical chemistry methods.

\section{Linearity and precision of the OLLIC}

The linearity of response and the precision of the photometer were evaluated according to the instructions of Broughton et al. (8). The mean absorbance and SD for each solution in the range $0.01-1.00$ are listed in table 4. Taking into account the standard deviations and
Tab. 4. Linearity and precision of the colorimeter. For all absorbance measurements $\mathrm{N}=96$.

\begin{tabular}{ccc}
\hline $\begin{array}{l}\text { A }\left(\times 10^{-3}\right) \\
\text { (calculated) }\end{array}$ & $\mathrm{A}\left(\times 10^{-3}\right)$ & $\mathrm{SD}$ \\
\hline 10 & 10.04 & 2.01 \\
25 & 24.47 & 1.13 \\
50 & 49.59 & 2.32 \\
75 & 75.26 & 1.36 \\
100 & 99.02 & 1.50 \\
200 & 199.38 & 2.61 \\
400 & 402.19 & 2.16 \\
600 & 594.83 & 4.10 \\
800 & 794.86 & 4.42 \\
1000 & 999.91 & 4.71 \\
\hline
\end{tabular}

an error in preparing the dilutions of cobalt(II)sulfate, the response was shown to be linear. After 500 burning hours of the xenon lamp (recommended life time $1000 \mathrm{~h}$ ), the linearity of the response of the photodetectors ranged up to an absorbance of 2.5 at $510 \mathrm{~nm}$. A precision of $1.3-4.7 \%$ for the colorimeter should be regarded as rather moderate. Therefore, we assume that equilibrium determinations with only small absorption changes will show considerably high coefficients of variation.

\section{Clinical tests}

\section{Within-run precision}

Four experiments $(\mathrm{N}=22-24)$ were performed on different days for alanine aminotransferase, creatinine and total protein, using lyophilised control sera in the low, medium and high range. The CV's for alanine aminotransferase ranged from $0.7-2.1 \%$, the CV's for creatinine ranged from $1.0-2.1 \%$ and the CV's for total protein ranged from $0.7-1.3 \%$.

\section{Between-day precision}

To test the between-day precision we reconstituted, on 30 separate days, lyophilised bovine control sera in the low, medium and high range for the three clinical assays on the OLLI CD and the comparison instruments (tab. 5). The coefficients of variation of alanine aminotransferase for both OLLI CD and the reference instrument were about $4 \%$ at the highest level. At the lower levels the precision on OLLI CD was slightly higher.

For creatinine the OLLI CD method showed a CV of about $2 \%$ for all three levels. However, the reference method had a better precision at the highest level.

The total protein assay showed a better precision on the reference instrument at all three levels.

The precision of the three individual assays for the OLLI $\mathrm{CD}$ was as good as or slightly worse than for the reference instruments. Nevertheless, the performance of the OLLI CD, as far as these tests are concerned, can still be considered to be good. 
Tab. 5. Between-day precision. For all mean values $\mathbf{N}=30$.

\begin{tabular}{|c|c|c|c|c|c|c|}
\hline \multirow[t]{2}{*}{ Assay } & \multicolumn{2}{|l|}{ Mean } & \multicolumn{2}{|l|}{ SD } & \multicolumn{2}{|l|}{$\overline{\mathrm{CV}}(\%)$} \\
\hline & $\begin{array}{l}\text { Reference } \\
\text { method }\end{array}$ & OLLII CD & $\begin{array}{l}\text { Reference } \\
\text { method }\end{array}$ & OLLI CD & $\begin{array}{l}\text { Reference } \\
\text { method }\end{array}$ & OLLI CD \\
\hline $\begin{array}{l}\text { Alanine aminotransferase } \\
(\mathrm{U} / \mathrm{l})\end{array}$ & $\begin{array}{r}20.5 \\
68.0 \\
102.4\end{array}$ & $\begin{array}{r}21.8 \\
68.3 \\
107.1\end{array}$ & $\begin{array}{l}0.8 \\
2.2 \\
3.2\end{array}$ & $\begin{array}{l}0.9 \\
2.7 \\
3.8\end{array}$ & $\begin{array}{l}4.0 \\
3.3 \\
3.1\end{array}$ & $\begin{array}{l}4.3 \\
4.0 \\
3.6\end{array}$ \\
\hline $\begin{array}{l}\text { Creatinine } \\
(\mu \mathrm{mol} / \mathrm{l})\end{array}$ & $\begin{array}{r}74.9 \\
198.5 \\
302.0\end{array}$ & $\begin{array}{r}79.9 \\
194.3 \\
293.9\end{array}$ & $\begin{array}{l}1.6 \\
3.2 \\
4.0\end{array}$ & $\begin{array}{l}1.7 \\
3.5 \\
6.3\end{array}$ & $\begin{array}{l}2.1 \\
1.6 \\
1.3\end{array}$ & $\begin{array}{l}2.1 \\
1.8 \\
2.1\end{array}$ \\
\hline $\begin{array}{l}\text { Total protein } \\
(\mathrm{g} / \mathrm{l})\end{array}$ & $\begin{array}{l}48.8 \\
71.4 \\
82.7\end{array}$ & $\begin{array}{l}47.6 \\
71.9 \\
84.9\end{array}$ & $\begin{array}{l}0.5 \\
0.7 \\
0.6\end{array}$ & $\begin{array}{l}0.7 \\
1.1 \\
1.2\end{array}$ & $\begin{array}{l}1.1 \\
0.9 \\
0.7\end{array}$ & $\begin{array}{l}1.5 \\
1.5 \\
1.4\end{array}$ \\
\hline
\end{tabular}

\section{Correlation studies}

The instruments were compared, using 150 patients' sera. Results from the OLLI CD were compared with those obtained on the LKB 8600 (alanine aminotransferase, 5-90 U/1, $30^{\circ} \mathrm{C}$ ) on the Mark II Autoanalyzer (creatinine, $40-200 \mu \mathrm{mol} / \mathrm{l}$ ) and on the SMA 6/60 Autoanalyzer (total protein, 40-85 g/l) (see figs. 1-3).

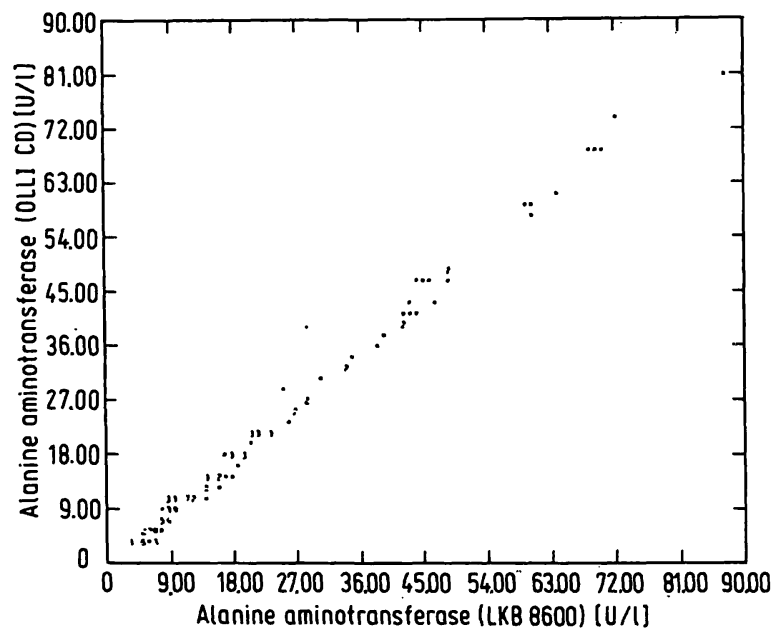

Fig. 1. Alanine aminotransferase comparison data for the results from the OLLI CD $(y)$ and the LKB $8600(x)$. From the rank correlation of Spearman and the rank sign test, $y=-0.2+x . \bar{x}=19.2$ and $\bar{y}=19.4$

In the correlation equation $y=a+b x$ the reference method is expressed as $\mathrm{x}$ and the OLLI method as $\mathrm{y}$.

Application of the rank correlation of Spearman with $\alpha=0.05$ did not result in a correlation $(b=1)$ between $(y-x)$ and $x$ for alanine aminotransferase ( $P($ two-sided) $=0.30)$ and creatinine $(\mathrm{P}($ two-sided $)=0.19)$. However, we found a positive correlation $(b=1)$ for total protein $(\mathrm{P}$ (two-sided $)<0.001)$.

To test for a systematical difference between the $\mathrm{x}$ and the $y$ determination for alanine aminotransferase and creatinine, the rank sign test was applied with $\alpha=0.05$.

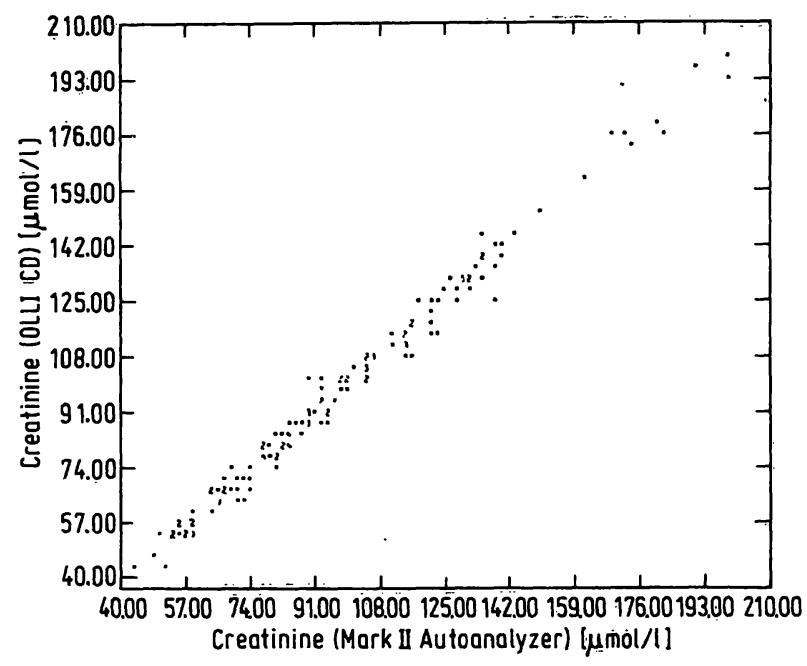

Fig. 2. Creatinine comparison data for the results from the OLLI CD (y) and the Mark II Autoanalyzer (x). From the rank correlation of Spearman and the rank sign test, $y=1.6+x . \bar{x}=100.7$ and $\bar{y}=102.3$.

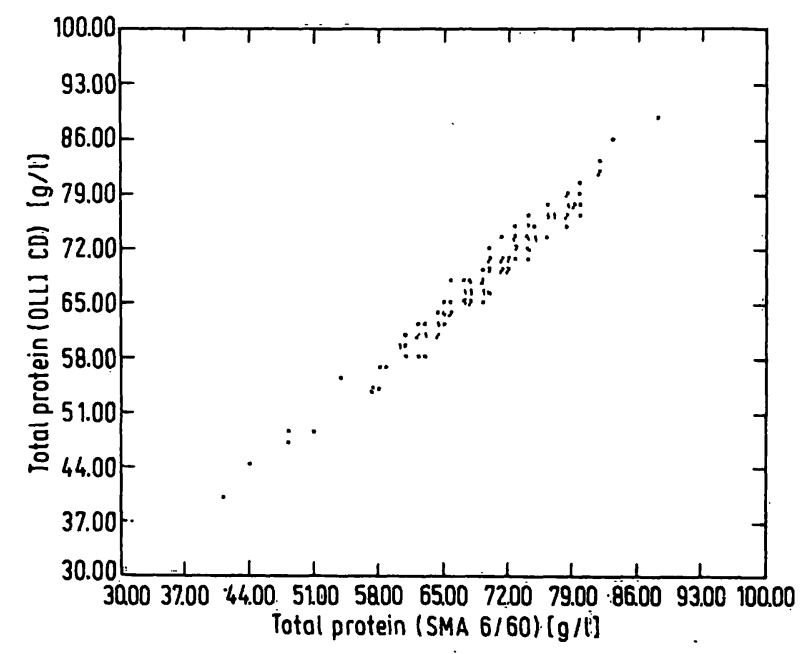

Fig. 3. Total protein comparison data for results from the OLLI CD (y) and the SMA 6/60 (x). The Deming correlation shows $y=4.12+1.052 \mathrm{x} \cdot \overline{\mathrm{x}}=68.90$ and $\bar{y}=68.36$ 
For alanine aminotransferase $(\mathrm{P}($ two-sided $)=0.008)$ as well as for creatinine $(\mathrm{P}$ (two-sided $)<0.001)$ a systematical difference was found. The alanine aminotransferase $y$ determination is on average $0.2 \mathrm{U} / 1$ lower than the $x$ determination. For creatinine the $y$ determination is on average $1.6 \mu \mathrm{mol} / 1$ higher than the $\mathrm{x}$ determination. These findings are reflected in the asymmetrical distributions of frequencies $(y-x)$ as shown in figures 4 and 5 for both assays. For total protein the correlation between $\mathrm{y}$ and $\mathrm{x}$ was estimated with the method of Deming, as recommended by Cornbleet et al. (9). Taking $\lambda=0.33$ as the proportion between the variations in $x$ and $y$, the equation reads $y=-4.12+1.052 \mathrm{x}$. The mean casual spreading of the $y$ determination around the regression curve was estimated at $\sigma_{\mathbf{y} . \mathbf{x}}=1.12 \mathrm{~g} / \mathrm{l}$.

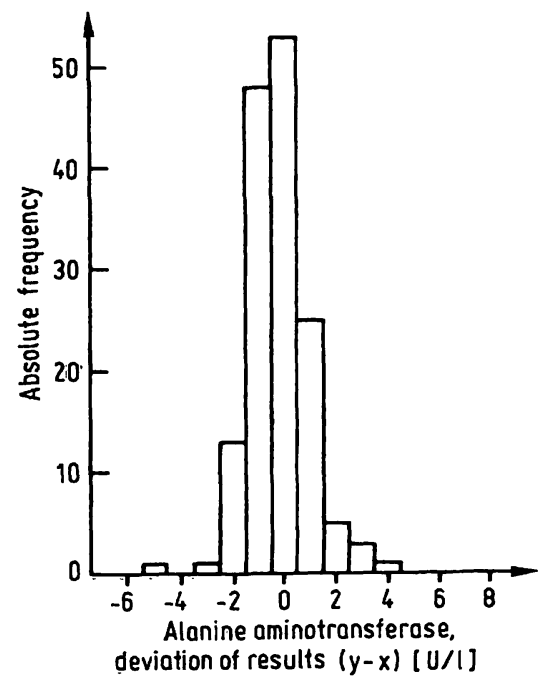

Fig. 4. Absolute frequency graph of deviations of alanine aminotransferase results: $y=$ OLLI CD; $x=$ LKB 8600 .

\section{Subjective assessment}

The OLLI CD is an advanced routine apparatus. Attractive features are its compactness and easy operation. The final volume in the cuvettes for measuring in the OLLI C

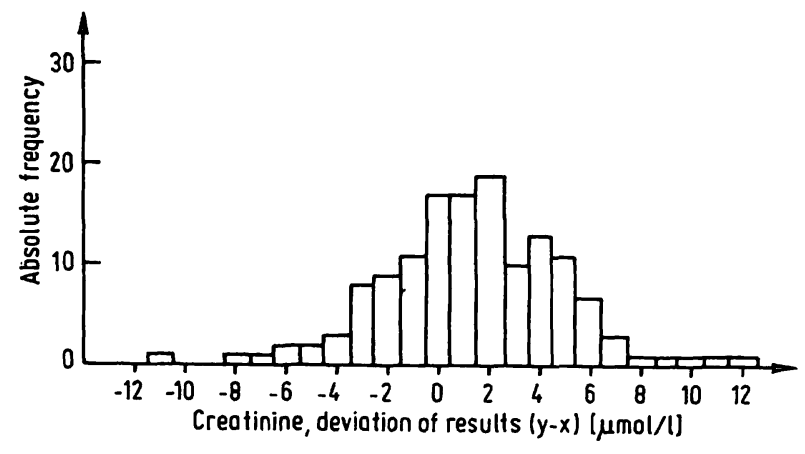

Fig. 5. Absolute frequency graph of deviations of creatinine results: $y=$ OLLI $C D ; x=$ Mark Il Autoanalyzer.

is $400 \mu \mathrm{l}$. We feel that this is too sharp an underlimit and therefore, we prefer to use minimal $500 \mu \mathrm{l}$. The manufacturer is currently attempting to reduce this required volume to $250 \mu \mathrm{l}$. The low sample size required, makes the OLLI CD appropriate for use in pediatrics. The manufacturer claims that the OLLI CD could process 500 cuvettes per hour by kinetic methods and 750 by equilibrium methods. To date, we perform the most requested enzyme assays on this instrument, thereby applying a $40 \mathrm{~s}$ delay time and a $60 \mathrm{~s}$ measuring time. We are able to process only half as many cuvettes in one hour. The same holds for the equilibrium assays. We feel it a drawback that the instrument does not allow a shorter delay time than about $35 \mathrm{~s}$ (of course, when only one row of 8 cuvettes of a block is used a shorter delay time is possible).

We predict that the OLLI CD will find application in middle-sized hospital laboratories.

\section{Acknowledgements}

We wish to express our gratitude to Drs. A. J. Coops, Radio Nucliden Centrum, for kindly making available laboratory equipment; Drs. P. A. R. Koopman, Medische Statistiek, for performing the statistical calculations in the correlation studies and to Dr. G. J. van Kamp, for critical reading of the manuscript.

\section{References}

1. Fröhlich, K., Jahn, A., Heck, M. \& Stolz, S. (1976) Acta Medicotechnica 24, 388-394.

2. Aanbevolen methoden voor het meten van kataly tische activiteits concentraties van enzymen in serum. (1979) Mededelingen Nederlandse Vereniging voor Klinische Chemie 4, 314-319.

3. Cheung, T. \& Briggs, M. H. (1974), Clin. Chim. Acta 54, 127-129.

4. Kammeraat, C. (1978) Clin. Chim. Acta 84, 119-128.
5. Chasson, A. L., Grady, H. J. \& Stanley, M. A. (1961) Am. J. Clin. Pathol. 35, 83-88.

6. Weichselbaum, T. E. (1946) Am. J. Clin. Pathol. 16, 40-49.

7. Skeggs Jr, L. T. \& Hochstrasser, H. (1964) Clin. Chem. 10, 918-936.

8. Broughton, P. M. G., Gowenlock, A. H., McCormack, J. J. \& Neill, D. W. (1974) Ann. Clin. Biochem. 11, 207-218.

9. Cornbleet, P. J. \& Gochman, N. (1979), Clin. Chem. 25, $432-438$.
Ir. G. A. Harff Department of Clinical Chemistry Academical Hospital, Frec University Postbus 7057 NL-1007 MB Amsterdam 
